\title{
Effects of Reciprocal Recurrent Selection on Grain Yield in Two Tropical-Temperate Maize Synthetic Populations Tuxpeño-Reid and Suwan-Lancaster
}

\author{
Zehui Chen, Yunfang Zhu, Angui Wang, Xiangyang Guo, Xun Wu*, Pengfei Liu \\ Upland Crops Institute, Guizhou Academy of Agricultural Sciences, Guiyang, China \\ Email: *wuxunyong@126.com
}

How to cite this paper: Chen, Z.H., Zhu, Y.F., Wang, A.G., Guo, X.Y., Wu, X. and Liu, P.F. (2019) Effects of Reciprocal Recurrent Selection on Grain Yield in Two Tropical-Temperate Maize Synthetic Populations Tuxpeño-Reid and Suwan-Lancaster. American Journal of Plant Sciences, 10, 298-308.

https://doi.org/10.4236/ajps.2019.102023

Received: December 19, 2018

Accepted: February 24, 2019

Published: February 27, 2019

Copyright $\odot 2019$ by author(s) and Scientific Research Publishing Inc. This work is licensed under the Creative Commons Attribution International License (CC BY 4.0).

http://creativecommons.org/licenses/by/4.0/

\begin{abstract}
Reid, Lancaster, Tuxpeño and Suwan are the most common maize (Zea mays $L$.) germplasms. Reid $\times$ Lancaster and Suwan $\times$ Tuxpeño are very important heterotic patterns in temperate areas and tropical areas, respectively. Broadening the genetic basis of maize has usually been conducted in inter-populations formed by crossing temperate and tropical germplasms. Reciprocal recurrent selection (RRS) is a breeding procedure to improve the inter-populational cross of two base populations. The objective of this study was to evaluate the direct and indirect effects of reciprocal recurrent selection on grain yield in the TR (Tuxpeño-Reid) and SL (Suwan-Lancaster) maize populations. The populations and the inter-populational crosses of each selection cycle, as well as two commercial hybrids, were evaluated in four environments. The effect of mean grain yield on TR $\times$ SL inter-population crosses was $4.63 \%$ (or 0.365 ${\mathrm{Mg} \cdot \mathrm{ha}^{-1} \text { ) cycle }}^{-1}$. The grain yield of SL increased by $2.78 \%$ (or $0.20 \mathrm{Mg} \cdot \mathrm{ha}^{-1}$ ) cycle $^{-1}$, but the grain yield of TR essentially did not change. Most changes in other agronomic traits occurred in the desired direction. After 3 selection cycles, the ear tip-barrenness length decreased in TR $\times$ SL, TR and SL by $39.70 \%, 37.50 \%$ and $24.57 \%$, respectively, which indicates that the increase in grain yield may be largely due to a decreasing ear tip-barrenness length. The mid-parent heterosis of grain yield of the inter-populational cross increased from $15.49 \%$ to $25.96 \%$ from C0 to C3. The mean grain yields of TRC $3 \times$ SLC3 were $100.01 \%$ and $103.88 \%$ of the mean grain yields of the commercial single-crosses GD8 and QD16, respectively. The results suggest that Tuxpeño-Reid $\times$ Suwan-Lancaster may be possible new heterotic patterns in the southern region of China.
\end{abstract}




\section{Keywords}

Reciprocal Recurrent Selection, Maize Germplasm, Population Improvement, Tropical

\section{Introduction}

Double-cycle breeding and the limited utilization of maize genetic diversity may substantially limit future genetic gains. The possibilities of including exotic germplasms in maize breeding programs have been emphasized [1]. To obtain gene combinations that have efficient biochemical functions within the genome, it is necessary to allow genetic recombination accompanied by mild selection. Lonnquist [2] emphasized the necessity and importance of recombination and the possible problems of linkage. The only recourse for the use of exotic germplasms in the US Corn Belt is patience and adequate recombination after several generations of random mating, with mild selection pressure [2] [3]. Troyer and Brown [4] demonstrated the effectiveness of gradual introductions of exotic germplasms into adapted germplasms from the US Corn Belt. They crossed Mexican germplasm with US Corn Belt lines and grew the crosses in isolated fields for 10 years to allow for recombination. From these materials, a few important lines were released that played large roles in US maize breeding.

Tuxpeño is one of the most productive and desirable races in Mexico and has been widely used in the Southern Dents of the USA. The Corn Belt Dent landrace was formed by the hybridization of the Southern Dent and Northern Flint races. Successive hybridizations were followed by a period of intermating and selection to gradually evolve the new races. Inter-racial hybridization seems to have been an important factor in the development of superior germplasms [5]. Following the suggestion of Wellhausen, Whitehead et al. [6] conducted an extensive program to integrate elite germplasm, developed by CIMMYT with elite lines of selected US Corn Belt germplasms in Iowa. Different heterotic groups were considered in making maize crosses: i.e., the subtropical maturity-BSSS crossed with Tuxpeño and non-BSSS crossed with non-Tuxpeño or the tropical maturity-BSSS crossed with Tuxpeño and non-BSSS crossed with non-Tuxpeño. Wellhausen [7] revealed the most widely used combinations for the immediate improvement of maize in the tropics: Tuxpeño and its related Caribbean and U.S. dents, Cuban Flint, Coastal Tropical Flint, and ETO.

Suwan-1 was developed at Suwan Farm in Thailand by using 36 sources, with most sources from the Caribbean Islands. Suwan-1 showed broad adaptation in tropical areas, strong tolerance to some diseases and insects, and an orange yellow flint. It was quite encouraging that the performance of the crosses derived from Suwan-1 crossed with CIMMYT populations 27, 28, and 24 was excellent. Suwan-1 is widely used for the development of maize hybrids in tropical or subtropical regions. 
Inter-population improvements have been initiated following Comstock et al. [8], and reciprocal recurrent selection has been proposed. Common sense would consider combining elite genetic material with genetic divergence to choose populations for improvement [9]. The improvement of maize parental germplasms is important not only for the developing of inbreds but also for the maize hybrid breeding process. Reciprocal recurrent selection is one cyclical breeding procedure designed to improve the inter-populational cross of two base populations [10]. The authors evaluated the responses of interpopulational crosses of BSSS and BSCB1 after 11 cycles of RRS. Grain yield increased 7.0\% per cycle of selection in the crossed population. Penny [11] reported a gain of $5.1 \%$ per cycle, as a direct response to the cross between population BSSS and BSCB1 after two cycles of RRS. Hallauer and Carena [1] showed that RRS could improve the population crosses (direct responses) with smaller changes (indirect responses) effectively when compared to each individual population.

The heterotic pattern of ETO crossed with Tuxpeño has been widely used during maize breeding in tropical regions all over the world, but the heterotic patterns of Suwan-1 crossed with Tuxpeño are still unknown [12]. Tuxpeño and Suwan-1 are two important maize germplasms in the southern region of China, where Reid $\times$ Suwan-1, Tuxpeño $\times$ Suwan- 1 and Tuxpeño $\times$ Lancaster are three major heterotic-using patterns [9]. Two populations of Tuxpeño-Reid and Suwan-Lancaster were developed by using the reciprocal half-sib recurrent selection method.

The objectives of this study are 1) to evaluate the responses to selection on maize grain yield and other agronomic traits for populations TR and SL as well as the population crossed between them after three cycles of reciprocal half-sib recurrent selections; 2) to identify the changes in heterosis between the TR and SL populations as a response to different selection generations; and 3) to discuss the potential ability of heterotic patterns by using Tuxpeño-Reid $\times$ Suwan-Lancaster in the southern region of China, through comparing the grain yield and other agronomic traits of Tuxpeño-Reid $\times$ Suwan-Lancaster with that of commercial hybrids.

\section{Materials and Methods}

The genetic materials used in this paper contain two artificial synthetic populations of TR and SL. TR was derived from 20 crosses made by four Tuxpeño inbreds $(405,449,9490,81,565)$ crossed with five Reid inbreds (B73, Ye478, 7922, Huang C, Zheng 58) in 2007 in Guiyang, Guizhou Province. The synthetic population of TRC 0 was constructed as follows: the 20 crosses were planted in an isolation area for random mating four times during 2008-2009 in Guiyang and Sanya, Hainan Province. The SL population was derived from 11 crosses made from Mo17 crossed with nine Suwan1 inbreds (S611, S37, QB17, QB39, QB40, QB44, QB48, QB137 and Ki32) and two 78,599 inbreds (78,599 and 18,599) in 2007 in Guiyang. The artificial synthetic population of SLC0 was constructed as follows: the 11 crosses were planted in an isolation area for random mating four 
times during 2008-2009, in Guiyang and Sanya.

Based on yield as an index trait, the artificial synthetic populations of SLC0 and TRC0 were subjected to three cycles of reciprocal half-sib recurrent selection. Then, 250 SLC0 plants were self-crossed, and pollen from the 250 plants was used to pollinate ten TRC0 (tester) ears. Each of the 250 self-crossed ears were shelled and stored separately. For testers, the seeds of each father plant were shelled in bulk. Similarly, 250 TRC0 self-crossed seeds and testcross seeds were obtained to describe SLC0. Then, 250 SLC0 $\times$ tester crosses and 250 TRC0 $\times$ tester crosses were evaluated separately in 2010 in Guiyang. The crosses were grown in one row plots, with a row length of $5.0 \mathrm{~m}$ spaced $0.7 \mathrm{~m}$ apart; there were two replications, a plant population density of 57,000 plants $\cdot \mathrm{ha}^{-1}$, and the crosses were performed using standard cultural management practices. Grain yields were recorded in $\mathrm{Mg} / \mathrm{ha}$ at $130 \mathrm{~g} \mathrm{H}_{2} \mathrm{O} \mathrm{kg}$. Based on the grain yield, the top 25 crosses of SLC0 $\times$ tester were identified, and relevant self-crossed ears were selected for random mating to form the SLC1 population. Similarly, TRC1 was also constructed as in the description above. The second and third cycles of reciprocal half-sib recurrent selection for grain yield were most similar to the first cycle. Then, the SLC2, SLC3, TRC2 and TRC3 populations were constructed from 2011 to 2015 in Sanya and Guiyang.

In 2016, eight of the populations (SLC0, SLC1, SLC2, SLC3, TRC0, TRC1, TRC2 and TRC3) were planted and inter-crossed by sib-mating. Each population was grown with 10 rows and 20 plants per row. Four types of crossing were performed: SLC0 $\times$ TRC0, SLC1 $\times$ TRC1, SLC2 $\times$ TRC2, and SLC $3 \times$ TRC3, which were produced in Sanya. Each plant was used as a male or as a female but never as both. Forty pollinated ears of each cross were harvested and shelled in bulk.

In 2017, the TR populations, SL populations, relevant crosses and two commercial hybrids, GD8 and QD16, were evaluated, with a completely randomized block design, with three replications in four environments: Guiyang $\left(26^{\circ} 50^{\prime} \mathrm{N}\right.$, $1050 \mathrm{~m}$ above sea level, Guizhou Province), Dafang $\left(27^{\circ} 20^{\prime} \mathrm{N}, 1550 \mathrm{~m}\right.$ above sea level, Guizhou Province), Sanya (18 $10^{\prime} \mathrm{N} 50 \mathrm{~m}$ above sea level, Hainan Province), Luoping $\left(25^{\circ} 10^{\prime} \mathrm{N}, 1480 \mathrm{~m}\right.$ above sea level, Yunnan Province). All the genotype experiments were grown in four-row plots, with a row length of $5.0 \mathrm{~m}$, spaced $0.7 \mathrm{~m}$ apart. The plant density was 57,000 plant $\cdot \mathrm{ha}^{-1}$, and standard cultural management practices were used. Grain yields were recorded in $\mathrm{Mg} / \mathrm{ha}$ at $130 \mathrm{~g} \mathrm{H}_{2} \mathrm{O} \mathrm{kg}{ }^{-1}$, and other agronomic traits were also measured. The phenotypes were investigated according to the methods reported by Wu et al. [13]. The grain yield-related traits were evaluated after harvest and after drying to a constant weight. Day to silking (DTS) was recorded when $50 \%$ of the plants exhibited silking. Plant height and ear height were recorded 20 days after pollination.

A phenotypic data analysis was performed according to the method reported by $\mathrm{Wu}$ et al. [13], and relevant calculations were performed using SAS software (Release 9.3; SAS Institute, Cary, NC). The means were compared by the LSD method. An ANOVA was performed using the PROC GLM model. Mid-parent heterosis was calculated as the difference between the mean of a population cross 
and the average of two parent populations.

\section{Results and Discussion}

For grain yield, the combined analysis of variance showed highly significant differences among environments and among genotypes. The combined analysis of variance across the four environments also showed highly significant differences among genotypes as well as a genotype $\times$ environment interaction. Detailed information is listed in Table 1.

For other agronomic traits, there were highly significant differences among environments and among genotypes. There were also highly significant differences in the environment $\times$ genotype interaction among other agronomic traits, except for ear row (significant) and ear tip-barrenness length (non-significant) (Table 1).

Because of reciprocal recurrent selection, grain yield, plant height, ear height and ear diameter all showed a similar trend. This result proves that this selection was effective and that it could be effective for improving grain yield of the inter-populational crosses. The grain yields of inter-populational crosses were 7.886, 8.254, 8.424 and $8.941 \mathrm{Mg} \cdot \mathrm{ha}^{-1}$ for the original population, after the first, second, and third cycles of selection, respectively. The genetic gain of the third cycle $(6.14 \%)$ was the highest, with the higher one being the first cycle $(4.67 \%)$ and the lowest one being the second cycle (2.06\%). The inter-populational crosses derived from SLC3 $\times$ TRC3 showed significantly better expression of grain yield than that of SLC0 $\times$ TRC0. The grain yield increased the cubic effect (Figure 1) during three cycles of reciprocal half-sib recurrent selection for grain yield, improving $0.365 \mathrm{Mg} \cdot \mathrm{ha}^{-1} \cdot \mathrm{cycle}^{-1}\left(4.63 \% \mathrm{cycle}^{-1}\right)$ (Table 2$)$. The difference in genetic gains for each cycle was probably caused by a different selection efficiency. These results were similar to the estimates obtained by Schnicker and Lamkey [14]. The authors compared the effects of reciprocal recurrent selection by using inter-populational crosses derived from the BASS and BSCB1 populations; their results showed that grain yield increased $0.25 \mathrm{Mg} \cdot \mathrm{ha}^{-1}$ per selection cycle (6.46\%). Their results indicated that reciprocal recurrent selection is effective in not only increasing the mean performances of the population crosses but also maintaining genetic variance. The results of this study show that reciprocal recurrent selection was effective for improving mean grain yield in the TR $\times$ SL population cross. Schnicker [14] reported that there was a 13.6\% yield increase in the Dent Composite population and a 7.8\% decrease in the Flint Composite population after the first cycle of RRS modification of HS-RRS2. The population cross increased $3.7 \%$ in the first cycle and $6.4 \%$ over the original cross after the second cycle. Hallauer and Carena [1] updated and summarized data for the results from inter-population improvement programs, where the average grain yield response in the population cross per cycle of selection was $4.8 \%$, ranging from $2.7 \%$ to $7.5 \%$. The number of selection cycles ranged from 1 to 11 . This summary agrees well with the estimated rate of gain of grain yield in our study: $4.63 \%$ per cycle. 


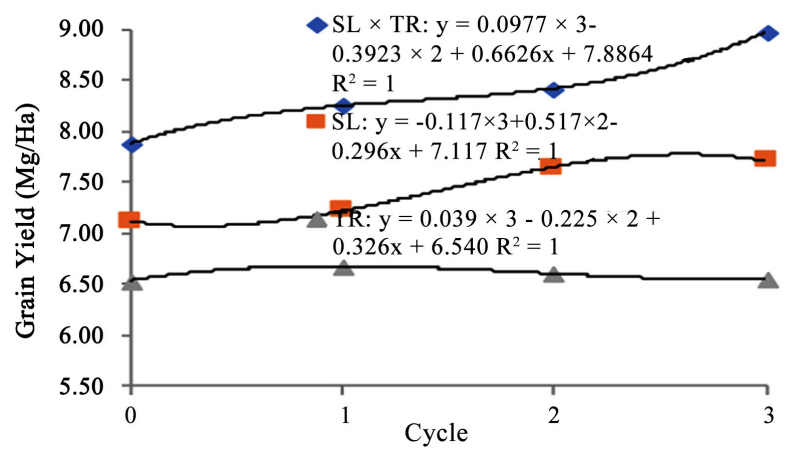

Figure 1. Grain yield of the population crosses and two populations after three cycles (C0, C1, C2, C3) of RRS for grain yield in the populations TR and SL. The cubic prediction equations are presented in the table. $\mathrm{Y}=$ grain yield; $\mathrm{X}=$ cycle of selection.

Table 1. ANOVA of grain yield and other agronomic traits.

\begin{tabular}{ccccccccccc}
\hline \multirow{2}{*}{$\begin{array}{c}\text { Variation } \\
\text { Source }\end{array}$} & DDffffDf & \multicolumn{10}{c}{ Mean square } \\
\cline { 3 - 10 } & & GY* & DTS & PH & EH & EL & ED & ETBL & ER & KN \\
\hline Environment & 3 & $62.96^{* *}$ & $3479^{* *}$ & $38361^{* *}$ & $26615^{* *}$ & $26.69^{* *}$ & $1.28^{* *}$ & $2.27^{* *}$ & $7.71^{* *}$ & $51.50^{* *}$ \\
Genotype & 13 & $9.69^{* *}$ & $9.93^{* *}$ & $1892^{* *}$ & $1326^{* *}$ & $2.290^{* *}$ & $0.21^{* *}$ & $2.27^{* *}$ & $4.69^{* *}$ & $23.32^{* *}$ \\
Env. $\times$ Geno. & 39 & $1.18^{* *}$ & $2.53^{* *}$ & $246.4^{* *}$ & $174.5^{* *}$ & $0.954^{* *}$ & $0.04^{* *}$ & 0.204 & $0.51^{*}$ & $6.84^{* *}$ \\
Error & 78 & 0.56 & 1.28 & 110.7 & 62.29 & 0.394 & 0.014 & 0.147 & 0.28 & 2.66 \\
\hline
\end{tabular}

${ }^{*}$ GY: grain yield, DTS: days to silking, PH: plant height, EH: ear height, EL: ear length, ED: ear diameter, ETBL: ear tip-barrenness length, ER: ear row, KN: kernel number per row. ${ }^{*}$ significant at the 0.05 probability level. ** significant at the 0.01 probability level.

Table 2. Means of grain yield and other agronomic traits in the original population, the improved synthetic population, the interpopulational crosses and the hybrid checks.

\begin{tabular}{cccccccccc}
\hline Genotype & $\begin{array}{c}\mathrm{GY}^{*} \\
\left(\mathrm{Mg} \mathrm{ha}^{-1}\right)\end{array}$ & DTS $(\mathrm{d})$ & $\begin{array}{c}\mathrm{PH} \\
(\mathrm{cm})\end{array}$ & $\mathrm{EH}(\mathrm{cm})$ & $\mathrm{EL}(\mathrm{cm})$ & $\mathrm{ED}(\mathrm{cm})$ & $\mathrm{ETBL}(\mathrm{cm})$ & ER & KN \\
\hline SLC0 $\times$ TRC0 & 7.886 & 86.8 & 252.3 & 102.4 & 18.4 & 5.2 & 2.62 & 13.9 & 32.5 \\
SLC1 $\times$ TRC1 & 8.254 & 85.9 & 260.7 & 104.7 & 18.8 & 5.2 & 1.96 & 14.7 & 34.4 \\
SLC2 $\times$ TRC2 & 8.424 & 85.8 & 262.0 & 107.9 & 18.5 & 5.1 & 1.72 & 14.6 & 34.9 \\
SLC3 $\times$ TRC3 & 8.981 & 86.3 & 265.8 & 108.4 & 19.2 & 5.1 & 1.58 & 14.8 & 36.4 \\
TRC0 & 6.540 & 87.8 & 226.6 & 86.6 & 17.6 & 5.1 & 1.52 & 13.6 & 33.1 \\
TRC1 & 6.680 & 86.3 & 234.4 & 89.6 & 18.1 & 5.0 & 1.72 & 13.7 & 33.4 \\
TRC2 & 6.605 & 86.4 & 233.9 & 88.3 & 18.0 & 5.1 & 1.52 & 14.2 & 34.3 \\
TRC3 & 6.550 & 87.3 & 239.6 & 91.4 & 17.6 & 4.9 & 0.95 & 14.4 & 35.1 \\
SLC0 & 7.117 & 87.2 & 249.0 & 102.4 & 17.9 & 5.2 & 2.32 & 14.8 & 31.2 \\
SLC1 & 7.221 & 87.4 & 257.8 & 107.4 & 18.1 & 5.1 & 1.69 & 14.5 & 34.1 \\
SLC2 & 7.653 & 85.8 & 251.7 & 103.6 & 18.5 & 5.0 & 1.85 & 14.3 & 33.3 \\
SLC3 & 7.71 & 87.3 & 255.1 & 111.1 & 18.4 & 5.1 & 1.75 & 15.0 & 34.5 \\
GD8 hybrid & 8.98 & 86.9 & 262.3 & 122.6 & 18.1 & 5.4 & 1.64 & 14.0 & 31.6 \\
QD16 hybrid & 8.646 & 89.2 & 263.5 & 113.7 & 17.9 & 5.2 & 0.99 & 16.0 & 34.5 \\
LSD $(0.05)$ & 0.607 & 0.92 & 8.55 & 6.41 & 0.51 & 0.10 & 0.31 & 0.43 & 1.33 \\
\hline
\end{tabular}

${ }^{*}$ GY: grain yield, DTS: days to silking, PH: plant height, EH: ear height, EL: ear length, ED: ear diameter, ETBL: ear tip-barrenness length, ER: ear row, KN: kernel number per row. 
For the TR population, the grain yield was almost unchanged after three cycles of selection, while a slight increase was observed for the SL population. The increases in the TR and SL grain yields showed a cubic change trend (Table 2, Figure 2). This result is consistent with some previous reports. In one study, two synthetic cultivars of BSSS and BSCB1 were compared. The results showed that RRS could improve the performance of inter-populational crosses (direct response, $6.95 \% \mathrm{cycle}^{-1}$ ), but the grain yield of BSCB1 increased $1.94 \% \mathrm{cycle}^{-1}$, and the grain yield of BSSS did not change significantly [10].

During the RRS improvement of grain yield, some other agronomic traits also showed positive changes, but the additive correlation between yield and other traits was still lower [12]. Most of the changes in other agronomic traits in our study were in the desired direction (Table 2). There were significance differences between SLC0 $\times$ TRC0 and SLC $3 \times$ TRC3 in terms of plant height, ear length, ear diameter, ear tip-barrenness length, ear row, and kernel number. Between SLC0 $\times$ TRC0 and SLC3 $\times$ TRC3, no significant differences were found for days to silking or for ear height.

The plant height of SLC3 $\times$ TRC3 significantly increased $13.5 \mathrm{~cm}(5.35 \%)$ for the third cycle of selection compared to SLCO $\times$ TRC0. Otherwise, ear diameter was significantly lower than SLC0 $\times$ TRC0. Although the plant height and ear diameter are not the selection targets during maize breeding, they are significantly correlated with grain yield; thus, these traits should be improved during artificial selection on maize grain yield. It seems that increases in ear length, ear row and kernel number and decreases in ear tip-barrenness length significantly increased the grain yield. Ding et al. [15] mapped three additive effects quantitative trait loci for ear tip-barrenness length on chromosomes 2, 3 and 6 . They explained $16.6 \%$ of phenotypic variation, and there were no significant QTL $\times$ environment interactions or digenetic interactions. The maize ear tip-barrenness trait types are controlled by two duplicate dominant genes, and tip-barrenness type is dominant over tip-barrenness type. Ear tip-barrenness length is a quantitative character controlled by a polygene, with major genes expected to have a role [16]. In this study, our results showed that selection on decreasing ear tip-barrenness length of a population cross was effective, and the decreasing trend in ear tip-barrenness length is linear (Figure 3), with decreasing values for TR $\times$ SL, TR and SL of $39.70 \%, 37.50 \%$ and $24.57 \%$, from C0 to C3, respectively (Table 2). This result indicates that the increase in grain yield may be mainly due to a decrease in ear tip-barrenness length.

For days to silking (DTS), no significant change was found during population improvement. This result shows that DTS remained unchanged for TR $\times$ SL as well as for the TR and SL populations after three cycles of reciprocal recurrent selection. This outcome may be because there is little difference in DTS between the TR and SL populations. However, this result is inconsistent compared to previous reports. There was a 6-d difference between BSSS(R) C0 and BSCB1(R) $\mathrm{C} 0$ for both silking and pollen dates. The changes in silking and pollen dates of 
the inter-populational crosses were not significant. The changes in silking and pollen dates in the original populations were due to the selection of plants in each population to produce the test crosses [10] (Table 3).

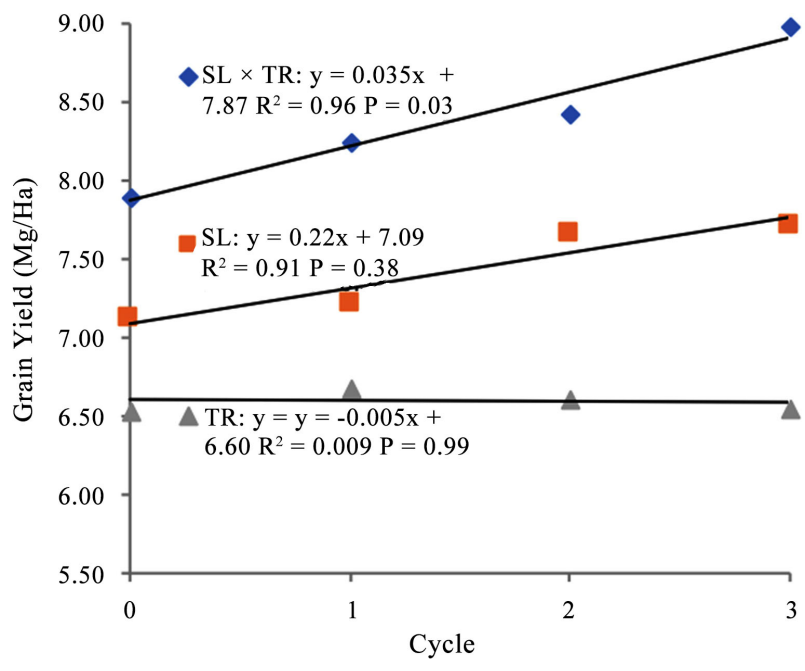

Figure 2. Grain yield of the population crosses and two populations after three cycles (C0, C1, C2, C3) of RRS for grain yield in the populations TR and SL. The linear prediction equations are presented in the table. $\mathrm{Y}=$ grain yield; $\mathrm{X}=$ cycle of selection.

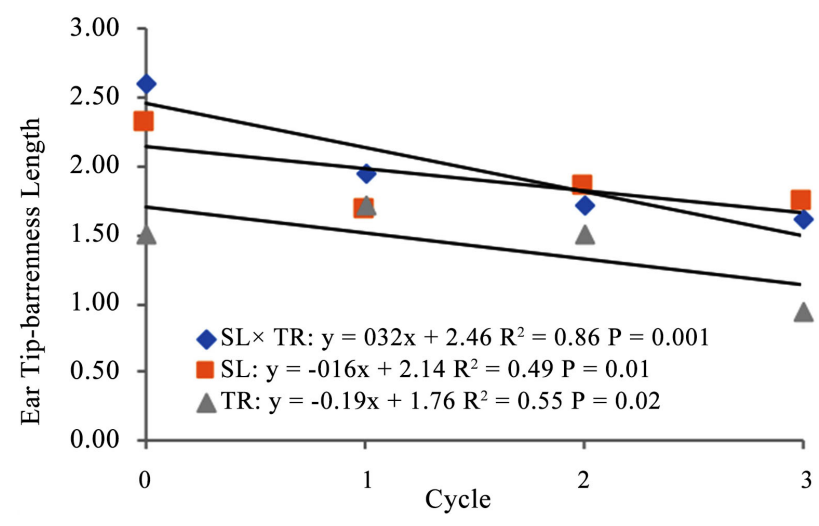

Figure 3. Ear tip-barrenness length of the population crosses and two populations after three cycles $(\mathrm{C} 0, \mathrm{C} 1, \mathrm{C} 2, \mathrm{C} 3)$ of RRS for grain yield in the populations TR and SL. The linear prediction equations are presented in the table. $\mathrm{Y}=$ grain yield; $\mathrm{X}=$ cycle of selection.

Table 3. Mid-parent heterosis of grain yield and other agronomic traits.

\begin{tabular}{cccccccccc}
\hline Cycle & $\mathrm{GY}^{*}(\%)$ & $\mathrm{DTS}(\%)$ & $\mathrm{PH}(\%)$ & $\mathrm{EH}(\%)$ & $\mathrm{EL}(\%)$ & $\mathrm{EWD}(\%)$ & $\mathrm{TIPL}(\%)$ & $\mathrm{ERN}(\%)$ & $\mathrm{KN}(\%)$ \\
\hline $\mathrm{C} 0$ & 15.49 & -0.8 & 6.09 & 8.36 & 3.66 & 0.97 & 36.46 & -2.11 & 1.09 \\
$\mathrm{C} 1$ & 18.75 & -1.2 & 5.93 & 6.29 & 3.87 & 2.97 & 14.96 & 4.26 & 1.93 \\
$\mathrm{C} 2$ & 18.17 & -0.3 & 7.91 & 12.45 & 1.37 & 0.99 & 20.77 & 2.46 & 3.25 \\
$\mathrm{C} 3$ & 25.96 & -1.2 & 7.46 & 7.06 & 6.67 & 2.00 & 17.04 & 0.68 & 5.75 \\
\hline
\end{tabular}

${ }^{*}$ GY: grain yield, DTS: days to silking, PH: plant height, EH: ear height, EL: ear length, ED: ear diameter, ETBL: ear tip-barrenness length, ER: ear row, KN: kernel number per row. 
Plant heights in TR $\times$ SL and in the TR population increased significantly and increased slightly in the SL population after three cycles of reciprocal recurrent selection. The gains obtained were 5.35\%, 5.74\% and $2.45 \%$. Conversely, the ear height of the SL population increased significantly and increased only slightly for the TR $\times$ SL and the TR populations. The gains obtained were $8.50 \%, 5.86 \%$ and $5.54 \%$ (Table 2). These results are inconsistent with the reports of Keeratijakal and Lamkey [10]. In their study, the plant height of inter-populational cross of BSSS and BSCB1 increased, but the ear height decreased compared to the populations. Schnicker and Lamkey [14] reported that grain yield had significant phenotypic correlations with grain moisture, stalk lodging, plant height and ear height in all three population crosses. Grain yield showed positive correlations with grain moisture, stalk lodging, and plant and ear height. Therefore, the increase in grain yield was accompanied by an increase in plant and ear height. The above summary is in good agreement with the results of our three cycles RRS for the TR and SL populations.

Recurrent selection methods can be used to develop new heterotic groups or to provide supplemental information for the improvement of existing heterotic groups. For grain yield, the mid-parent heterosis did not change significantly when the original population was crossed to the improved populations with three cycles of selection [17]. In this study, the mid-parent heterosis of grain yield increased significantly when compared to TRC0 $\times$ SLC0 (15.49\%) and TRC3 $\times$ SLC3 (25.96\%). After three cycles of selection, the mid-parent heterosis of ear tip-barrenness length decreased significantly from $36.46 \%$ of TRC $\times$ SLC0 to $17.04 \%$ of TRC3 $\times$ SLC3. This result is consistent with the increase in mid-parent heterosis for grain yield in the inter-population crosses reported by Keeratijakal, with $0.22 \mathrm{Mg} \cdot \mathrm{ha}^{-1}$ per cycle, or, expressed as a percentage of mid-parent, an increase from $25.44 \%$ to $76.04 \%$ after 11 cycles of reciprocal recurrent selection in the BSSS and BSCB1 maize populations [10]. The increase in heterosis was primarily a result of the increase in grain yield of the inter-population crosses. The heterosis pattern of Tuxpeño-Reid $\times$ Suwan-Lancaster in south China was first proposed by Chen et al. [9] with the populations involved in this study. To compare commercial hybrids, the mean grain yield of TRC3 $\times$ SLC3 was $100.01 \%$ and $103.88 \%$ of the mean grain yields of commercial single-cross lines, GD8 and QD16, respectively, and other agronomic traits were similar or better than those of GD8 and QD16. This result suggests that Tuxpeño-Reid $\times$ Suwan-Lancaster are possible new heterotic patterns in the south of China.

These results indicate that RRS was effective for improving grain yield and other important agronomic traits in the inter-populational crosses between the TR and SL populations used in this study. One of the objectives of our maize breeding program is to develop synthetic tropical-temperate maize populations that can be used as sources for developing new inbreds for modern maize breeding. This work is a step toward this objective. 


\section{Acknowledgements}

This research was supported by the National Key Research and Development Program of China (2016YFD0101206), the Innovation Program of QAAS (Special character of independent innovation of Guizhou Academy of Agriculture (2014) 006), the National Natural Science Foundation (31760387), the Science and Technology Project of Guizhou Province (Qiankehe Foundation [2017] 1413, Qiankehe platform talent ([2018] 5629) and Qiankehe support [2018] 2296, [2017] 2507 and [2017] 2504-1).

\section{Conflicts of Interest}

The authors declare no conflicts of interest regarding the publication of this paper.

\section{References}

[1] Hallauer, A.R. and Carena, M.J. (2009) Maize Breeding. In: Carena, M.J., Ed., Handbook of Plant Breeding. Cereals, 3-98.

[2] Lonnquist, J.H. (1974) Consideration and Experiences with Recombinations of Exotic and Corn Belt Maize Germplasms. Annu. Corn Sorghum Res. Conf. Proc., 29, 102-117.

[3] Brown, W.L. (1953) Maize of the West Indies. Trop. Agric., 30, 141-170.

[4] Troyer, A.F. and Brown, W.L. (1972) Selection for Early Flowering in Corn. Crop Science, 12, 301-304.

[5] Wellhausen, E.J., Roberts, L.M., Hernandez, E.X., et al. (1952) Races of Maize in Mexico. Bussey Inst. Harvard University Press, Cambridge, 1-36.

[6] Whitehead, F.C., Caton, H.G., Hallauer, A.R., et al. (2006) Incorporation of Elite Subtropical and Tropical Maize Germplasm into Elite Temperate Germplasm. Maydica, 51, 43-56.

[7] Wellhausen, E.J. (1965) Exotic Germplasm for Improvement of Corn Belt Maize. Annu. Hybrid Corn Res. Conf. Proc., 20, 31-45.

[8] Comstock, R.E., Robinson, H.F. and Harvey, P.H. (1949) A Breeding Procedure Designed to Make Maximum Use of Both General and Specific Combining Ability. Agronomy Journal, 41, 360-367.

[9] Chen, Z.H., Zhu, Y.F., Wang, A.G., et al. (2013) Two Maize Populations of Tuxpeno-Reid and Suwan-Lancaster by Reciprocal Recurrent Selection and the Heterosis. Journal of Maize Science, 21, 5-10.

[10] Keeratinijakal, V. and Lamkey, K.R. (1993) Responses to Reciprocal Recurrent Selection in BSSS and BSCB1 Maize Populations. Crop Science, 33, 73-77.

[11] Penny, L.H. (1959) Improving Combining Ability by Recurrent Selection. Annu. Hhybrid Corn Ind. Res. Conf. Proc., 14, 7-11.

[12] Hallauer, A.R., Russell, W.A. and Lamkey, K.R. (1988) Corn Breeding. In: Sprague, G.F. and Dudley, J.W., Eds., Corn and Corn Improvement, 3rd Edition, 533-534.

[13] Wu, X., Li, Y., Li, X., Li, C., Shi, Y., Song, Y., et al. (2015) Analysis of Genetic Differentiation and Genomicvariation to Reveal Potential Regions of Importance during Maize Improvement. BMC Plant Biology, 15, e256.

[14] Schnicker, B.J. and Lamkey, K.R. (1993) Interpopulation Genetic Variance after Reciprocal Recurrent Selection in BSSS and BSCB1 Maize Populations. Crop Science, 
33, 90-95.

[15] Ding, J., Ma, J., Chen, J., et al. (2016) QTL Mapping for Ear Tip-Barrenness in Maize. Spanish Journal of Agricultural Research, 14, 36-42. https://doi.org/10.5424/sjar/2016143-9325

[16] Meng, Z.-D., Zhang, F.-J., Ding, Z.-H., et al. (2007) Inheritance of Ear Tip-Barrenness trait in Maize. Agricultural Sciences in China, 6, 628-633. https://doi.org/10.1016/S1671-2927(07)60092-3

[17] Vales, M.I., Malvar, R.A., Revilla, P., et al. (2001) Recurrent Selection for Grain Yield in Two Spanish Maize Synthetic Populations. Crop Science, 41, 15-19. 